\title{
Renal Benign Mesenchymoma
}

National Cancer Institute

\section{Source}

National Cancer Institute. Renal Benign Mesenchymoma. NCI Thesaurus. Code C84256.

A benign mesenchymoma arising from the kidney. 